\title{
Split-hand/split-foot malformation (SHFM)
}

\author{
Monojit Mondal', Kriti Sundar Rana', Nayan Banerji', Sayan Bose', Tanmoy Biswas', Biswajit Biswas², \\ Pijush Kanti Mandal ${ }^{3}$
}

${ }^{1}$ Junior Resident, ${ }^{2}$ Asst. Professor, Department of Pediatric Medicine, Burdwan Medical College, Burdwan, ${ }^{3}$ Senior Resident, General

Medicine, ESI PGIMSR, Maniktala, Kolkata, India

\section{A B S T R A C T}

Split-hand/split-foot malformation (SHFM), also known as ectrodactyly or lobster claw hand is a congenital limb malformation, characterized by a deep median cleft of the hand and/or foot due to the absence of the central rays of the autopod. It may occur singly or in association with syndromes, former being mostly autosomal dominant but autosomal recessive variety is Access this article online Website:

http://nepjol.info/index.php/AJMS rare. We are reporting a case of ectrodactyly with autosomal recessive mode of inheritance.

Key words: Split-hand/split-foot malformation, Ectrodactyly, Autosomal recessive

\section{INTRODUCTION}

Split-hand/split-foot malformation is a limb malformation involving the central rays of the autopod and presenting with syndactyly, median clefts of the hands and feet, and aplasia and/or hypoplasia of the phalanges, metacarpals, and metatarsals. It may look like lobster claw if there is absence of third digit with clefting into the proximal portion of the hand or foot and syndactyly of remaining digit on each side of cleft. ${ }^{1-3} \mathrm{~A}$ large number of human gene defects can cause SHFM. The most common mode of inheritance is autosomaldominant with reduced penetrance. Autosomal-recessive and $\mathrm{X}$-linked forms occur rarely and other cases of SHFM are caused by chromosomal deletions and duplications. ${ }^{4,5}$

\section{CASE REPORT}

\section{History}

A term, appropriate for gestational age (AGA), female neonate delivered vaginally at a rural hospital of West Bengal, India, presented on day 2 with deformed hand and foot. She was born out of consanguineous marriage belonging to a poor socioeconomic family. Antenatal and intranatal periods were uneventful.

\section{On Examination}

Neonate weighed $2.6 \mathrm{Kg}$, cry, reflex and activities were good, vitals and anthropometric measurements were within normal limit. There were absence of third digit and lobster claw appearance of right hand (Figure 1), syndactyly of left foot involving second and third toes (Figure 2). There was no other dysmorphic feature.

Our patient was third in birth order. The first sibling was a normal male baby, second was still born at term with no deformity. There was no history of similar malformation in the family.

\section{DISCUSSION}

The split-hand/split-foot malformation is a central reduction defect of the hands and feet and occurs both as an isolated malformation and as part of several syndromes including the EEC syndrome(ectrodactyly-ectodermal dysplasia cleft lip/palate). Its incidence has been reported to be about 1 in 90,000 babies with no sex predilection. SHFM is a clinically heterogeneous abnormality which ranges from a relatively mild defect such as hypoplasia of a single phalanx or syndactyly to the aplasia of one or more central digits (i.e. classical cleft also known as lobster-claw anomaly). In the majority of cases, SHFM is autosomal dominant with reduced penetrance and autosomal-recessive and $\mathrm{X}$-linked forms are rare. ${ }^{1-5}$ At least seven SHFM types (six basic from SHFM1 to SHFM6 and one additional SHFM/SHFLD) have been distinguished in the literature. Type I, the most frequent variety, is due 


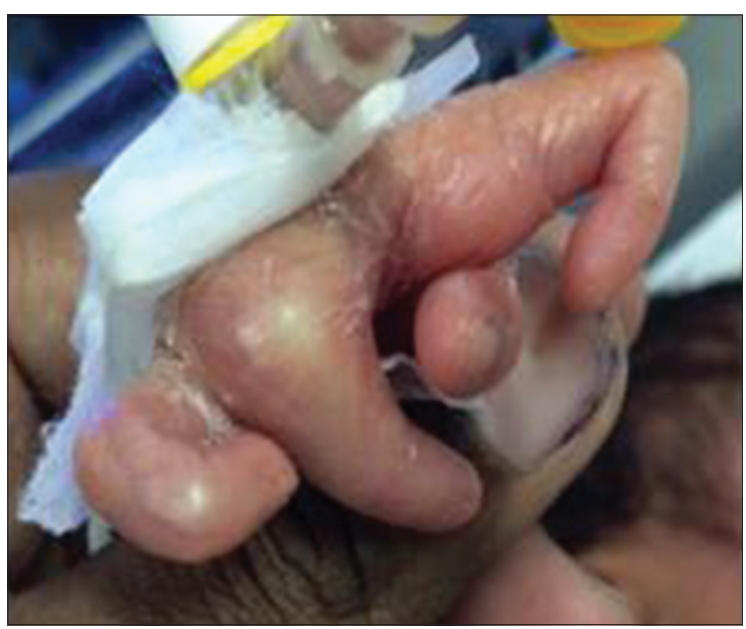

Figure 1: Lobster claw appearance of right hand

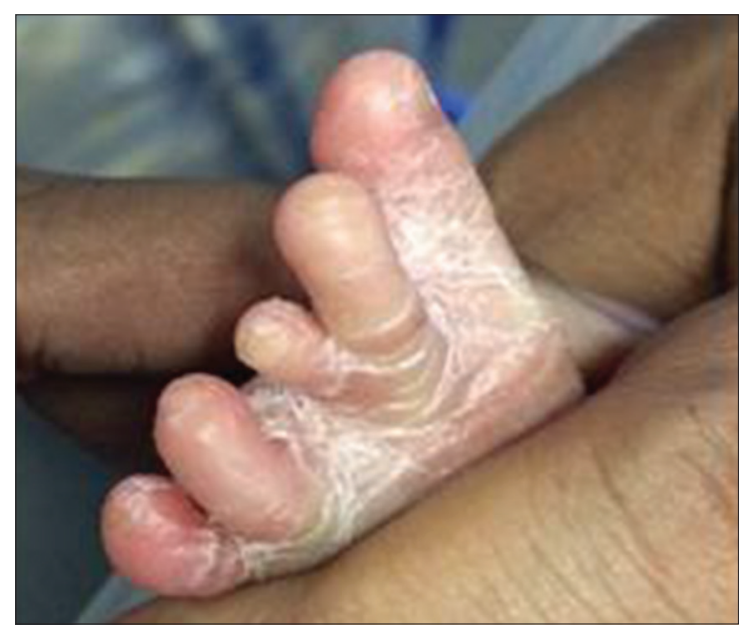

Figure 2: Syndactyly of left foot involving second and third toes

to a mutation on chromosome 7 (rearrangements in $7 \mathrm{q} 21.3-\mathrm{q} 22.1)$ in a region that contains two homeobox genes, DLX5 and DLX6. ${ }^{6-8}$

In our case, the mode of inheritance is autosomal reccesive as only one sibling and no other family members are affected. There have been isolated case reports in the literature of the autosomal recessive inheritance pattern of SHFMs of the non-syndromal type. Verma et al. described split-hand and split-foot in two siblings born out of consanguineous marriage and indicated that split hand and -foot deformity can be inherited as an autosomal recessive trait. ${ }^{9}$ Ray and Freire-Maia also reported autosomal recessive ectrodactyly. ${ }^{10-11}$
The treatment of ectrodactyly is surgical. Surgery can improve function and appearance of the limb. Prosthetics may also be used. Parents should be counselled regarding the possibility of recurrence of the disease in the future siblings and antenatal diagnosis by ultrasonography should be offered. ${ }^{12,13}$

\section{CONCLUSION}

The importance of reporting the case is to emphasize the need for early antenatal diagnosis and parental counselling regarding recurrence.

\section{REFERENCES}

1. Elliott $\mathrm{AM}$, Reed MH, Roscioli T and Evans JA. Discrepancies in upper and lower limb patterning in split hand foot malformation. Clin Genet 2005; 68(5):408-423.

2. Temtamy SA and McKusick VA. The genetics of hand malformations. New York: Wiley-Liss 1978: 53-71.

3. Buyse ML. Birth Defects Encyclopedia. Cambridge: Blackwell Scientific Publications 1990: 605-608.

4. Gul D and Oktenli C. Evidence for autosomal recessive inheritance of split hand/split foot malformation: a report of nine cases. Clin Dysmorphol 2002; 11(3):183-186.

5. Ahmad M, Abbas H, Haque $S$ and Flatz G. X-chromosomally inherited split-hand/split-foot anomaly in a Pakistani kindred. Hum. Genet 1987; 75(2):169-173.

6. Crackower MA, Scherer SW, Rommens JM, Hui CC, Poorkaj P, Soder S, et al. Characterization of the split hand/split foot malformation locus SHFM1 at 7q21.3- q22.1 and analysis of a candidate gene for its expression during limb development. Hum Mol Genet 1996; 5(5):571-579.

7. Blattner A, Huber $A R$ and Röthlisberger B. Homozygous nonsense mutation in WNT10B and sporadic split-hand/foot malformation (SHFM) with autosomal recessive inheritance. Am J Med Genet A 2010; 152 A(8):2053-2056.

8. Klopocki E, Lohan S, Doelken SC, Stricker S, Ockeloen CW, Thiele S, et al. Duplications of BHLHA9 are associated with ectrodactyly and tibia hemimelia inherited in non Mendelian fashion. J Med Genet 2012; 49(2):119-125.

9. Verma IC, Joseph R, Bhargava S and Mehta S. Split-hand and split-foot deformity inherited as an autosomal recessive trait. Clin Genet 1976;9(1):8-14.

10. Ray AK. Another case of split foot mutation in sibs. J Hered 1960; 61(4):169-170.

11. Freire-Maia A. A recessive form of ectrodactyly and its implications in genetic counselling. J Hered 1971; 62(1):53.

12. Pinette M, Garcia L, Wax JR, Cartin A and Blackstone J. Familial ectrodactyly. J Ultrasound Med 2006; 25(11):1465-1467.

13. Arbués J, Galindo A, Puente JM, Vega MG, Hernández M and de la Fuente P. Typical isolated ectrodactyly of hands and feet: Early antenatal diagnosis. J Matern Fetal Neonatal Med 2005; 17(4):299-301.

\section{Authors Contribution:}

MM, KSR - Drafting the manuscript and review of literature; NB, SB, TB - Work up and follow up of the case; BB, PKM - Editing and overall supervision.

Source of Support: Nil, Conflict of Interest: None declared. 